\title{
Evaluasi Program Ekstrakurikuler di Pondok Pesantren Al-khoir Padang Lawas Sumatera Utara
}

\author{
Nurhasanah Harahap ${ }^{1,2^{*}}$, Fahmi Rizal ${ }^{2}$ \\ ${ }^{1}$ Pesantren Al-khoir Padang Lawas Sumatera Utara \\ 1,2Program Studi Magister Pendidikan Teknologi dan Kejuruan Fakultas Teknik Universitas Negeri Padang \\ *Corresponding author, e-mail: nurhasanahharahapptk@gmail.com
}

\begin{abstract}
Abstrak - program ekstrakurikuler merupakan proses pembelajaran yang dilakukan di luar kelas. Ekstrakurikuler diadakan untuk menumbuhkan minat dan bakat santri, akan tetapi santri masih kurang berminat untuk mengikuti program ini. Sarana dan prasarana yang tersedia masih kurang. Penelitian ini bertujuan ntuk mengevaluasi program ekstrakurikuler di Pondok Pesantren Al-khoir Padang Lawas Sumatera Utara. Model evaluasi yang digunakan adalah model CIPP (context, input, process, dan product) dengan pendekatan Mix Method yaitu gabungan penelitian kuantitatif dan kualitatif. Subjek penelitian ini adalah seluruh yang terkait dalam ekstrakurikuler. Data kuantittif diperoleh dari siswa dengan cara mengisi angket dan untuk memperoleh data kualitatif yaitu dengan cara wawancara kepada informan. Hasil penelitian ini adalah ditinjau dari context yaitu dalam kategori baik. Untuk komponen input yaitu dalam kategori baik. Komponen process dengan kategori cukup. Dan untuk komponen product yaitu dengan kategori baik. Kesimpulannya adalah program ini termasuk dalam kategori baik hanya saja perlu pengoptimalan khusus pada komponen process dan untuk keseluruhan tetap perlu adanya perbaikan demi baiknya program ini kedepannnya.
\end{abstract}

Kata Kunci : Mix Method, CIPP, Ekstrakurikuler.

Abstract-extracurricular program is a learning process that is carried out outside the classroom. Extracurricular activities are held to foster the interests and talents of students, but students are still less interested in joining this program. Facilities and infrastructure available are still lacking. This research aims to evacuate the extracurricular program at Al-khoir Islamic Boarding School in Padang Lawas, North Sumatra. The evaluation model used is the CIPP model (context, input, process, and product) with the Mix Method approach, which is a combination of quantitative and qualitative research. The subjects of this research are all those involved in extracurricular activities. Quantitative data were obtained from students by filling out questionnaires and to obtain qualitative data by interviewing informants. The results of this study are in terms of context in the good category. For input components that are in either category. Process components with enough categories. And for the product component, which is in the good category. The conclusion is that this program is included in the good category only it needs special optimization on the process components and for the whole it still needs improvements for the good of the program going forward.

Keywords: Mix Method, CIPP, Extracurricular.

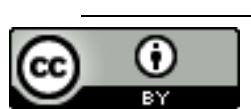

\section{PENDAHULUAN}

Pondok pesantren Al-khoir Padang Lawas Sumatera Utara merupakan lembaga pendidikan yang dikelola oleh yayasan ataupun swasta. Pondok pesantren Al-khoir terdiri dari Madrasah Tsanawiyah (MTs) dan Madrasah Aliyah (MA). Untuk seluruh santri diwajibkan tinggal diasrama. Jumlah keseluruhan santri adalah 355 santri.
Santri MTs berjumlah 200 santri dan untuk MA berjumlah 155 santri. Guru yang mengajar di Pondok Pesantren Al-khoir berjumlah 35 guru. Sarana dan prasarana yang ada dalam Pondok Pesantren adalah ruang guru, ruang kelas, asrama, kantin, koperasi, kamar mandi, lapangan sepak bola, laboratorium komputer, laboratorium menjahit serta dapur umum dan ruang makan 
santri. Selain belajar aktif disekolah santri juga memiliki kegiatan belajar mengajar diluar kelas yaitu ekstrakurikuler yang merupakan pengembangan minat dan bakat santri.

Program pengembangan bakat, minat dan prestasi peserta didik yang diistilahkan dengan ekstrakurikuler [1]. Pelaksanaannya diluar jam belajar intrakurikuler dibawah bimbingan dan pengawasan satuan pendidikan. Kepramukaan merupakan salah satu ekstrakurikuler wajib [2]. Ekstrakurikuler pilihan yaitu krida, karya ilmiyah, latihan olah bakat dan minat, keagamaan. Kegiatan ekstrakurikuler wajib diberikan kepada seluruh santri yang merupakan pelaksanaan kurikulum 2013, untuk ekstrakurikuler pilihan diberikan kepada seluruh santri sesuai minat dan bakat yang dipilihnya.

Berdasarkan wawancara dengan penanggung jawab ekstrakurikuler, program ini bertujuan untuk menggali bakat santri serta menemukan minat santri. Sehingga dengan adanya program ini santri akan lebih terarah dalam memilih bidang apa yang di minati serta bakatnya. Berdasarkan hal tersebut dapat disimpulkan bahwa tujuan dari program ini adalah untuk menyalurkan dan mengembangkan bakat dan minat santri untuk mewujudkan santri yang kreatif, sportif, serta berkompeten dalam bakat dan minatnya.

Program ekstrakurikuler pondok pesantren Alkhoir terbagi dua yaitu baguan tarbiyah (pembelajaran) dan riayah (pengasuhan). Bidang tarbiyah terdiri dari 4 jenis kegiatan yaitu pramuka, muhadharah (pidato), Study Club, dan komputer. Bidang riayah terdiri dari silat, tata boga, menjahit, dan kitab kuning. Program ekstrakurikuler dikelola oleh dua orang guru yaitu dibidang tarbiyah dan dibidang riayah. Sasaran kegiatan ini adalah seluruh santri serta santri bebas dalam memilih untuk mengikuti sesuai minat dan bakatnya.

Pelaksanaan kegiatan ekstrakurikuler dalam pengembangan minat dan bakat, diharapkan santri aktif dalam mengikutinya agar tujuan dari program tercapai. Berdasarkan wawancara dengan guru dan santri bahwa pelaksanaan pada santri putra kurang aktif.

Berdasarkan tabel 1 dapat dilihat bahwa peserta ekstrakurikuler santri putra lebih sedikit dibandingkan santri putri yang lebih aktif dalam mengikuti setiap kegiatannya. Dengan demikian dapat disimpulkan bahwa minat santri masih kurang.

Dalam suatu kegiatan ekstrakurikuler yang paling dibutuhkan adalah sarana dan prasara untuk mendukung kegiatan yang dilakukan. Berdasarkan observasi bahwa sarana dan prasarana kegiatan masih kurang.

Tabel 1. Data santri mengikuti Ekstrakurikuler

\begin{tabular}{|c|l|l|l|}
\hline No & \multicolumn{1}{|c|}{ Nama Kegiatan } & $\begin{array}{c}\text { Jumlah } \\
\text { santri } \\
\text { putra }\end{array}$ & $\begin{array}{l}\text { Jumlah } \\
\text { santri } \\
\text { putri }\end{array}$ \\
\hline 1 & Muhadharah (wajib) & $\begin{array}{l}\text { Seluruh } \\
\text { Santri }\end{array}$ & $\begin{array}{l}\text { Seluruh } \\
\text { Santri }\end{array}$ \\
\hline 2 & Pancak silat (wajib) & $\begin{array}{l}\text { Seluruh } \\
\text { Santri }\end{array}$ & $\begin{array}{l}\text { Seluruh } \\
\text { Santri }\end{array}$ \\
\hline 3 & Pramuka (wajib) & $\begin{array}{l}\text { Seluruh } \\
\text { Santri }\end{array}$ & $\begin{array}{l}\text { Seluruh } \\
\text { Santri }\end{array}$ \\
\hline 4 & Komputer (pilihan) & 40 & 40 \\
\hline 5 & Study club(pilihan) & - & 80 \\
\hline 6 & Menjahit (pilihan) & - & 48 \\
\hline 7 & Tata Boga (pilihan) & - & 36 \\
\hline 8 & KitabKuning (pilihan) & 8 & 28 \\
\hline
\end{tabular}

Dilihat dari masalah diatas program ekstrakurikuler perlu dievaluasi untuk memperbaiki program yang telah direncanakan hingga lebih efektif untuk digunakan serta dapat bermanfaat untuk sekolah dan sekolah lain.

Program adalah segala sesuatu yang dicoba lakukan seseorang dengan harapan akan mendatangkan hasil dan pengaruh [3]. Program adalah sebagai suatu unit atau kesatuan kegiatan yang merupakan realisasi atau implementasi dari suatu kebijakan, terjadi dalam proses yang berkesinambungan dan terjadi dalam suatu organisasi yang melibatkan sekelompok orang [4].

Berdasarkan surat keputusan Mentri Pendidikan dan Kebudayaan No. 060/U/1993 dan Nomor 080/U/1993 kegiatan ekstrakurikuler adalah kegiatan yang diselenggarakan diluar jam pelajaran yang tercantum dalam susunan program sesuai dengan keadaan dan kebutuhan sekolah dan dirancang secara khusus agar sesuai dengan factor minat dan bakat siswa.

Dalam kerangka berpikir ini terdapat model CIPP. Untuk komponen konteks aspek yang dilihat yaitu kebutuhan program dan tujuan program. Untuk komponen input aspek yang dilihat yaitu sumber daya manusia, sarana dan prasarana, serta metode pelaksanaannya. Untuk komponen proses yaitu melihat dari aspek pelaksanaan program, menilai kinerja program, serta kendala pelaksanaan program. Dan yang terakhir yaitu komponen produk yang melihat dari segi aspek hasil dari pelaksanaan kegiatan program minat dan bakat yang telah dilalui. Penelitian ini diharapkan dapat memberikan rekomendasi baik dan tepat untuk keberlangsungan kegiatan minat dan bakat di 
pondok pesantren Al-khoir agar kegiatan tersebut dapat dilaksanakan lebih baik lagi. Kerangka berpikir penelitian ini dapat dilihat pada Gambar 1.

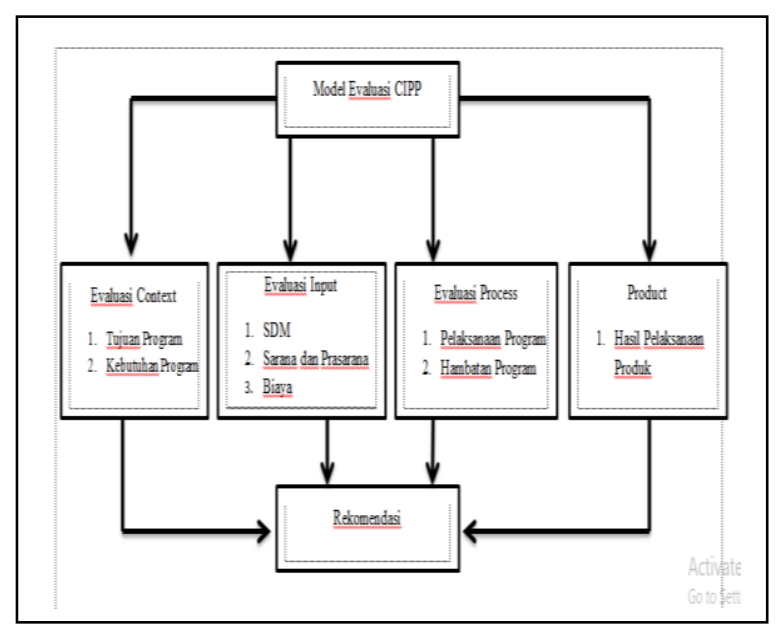

Gambar 1. Kerangka Konseptual.

\section{METODA}

Penelitian ini adalah penelitian evaluasi program. Model Evaluasi yang digunakan pada penelitian ini adalah model yang dikembangkan oleh Stufflebeam yaitu model evaluasi CIPP (context, input, process, product).[5] Metode penelitian yang digunakan adalah metode penelitian gabungan (mixed method). Metode penelitian gabungan adalah metode penelitian yang menggunakan pendekatan penelitian kualitatif dan kuantitatif pada satu proses penelitian [6].

Lokasi penelitian ini dilakukan di Pondok pesantren Al-khoir yang berlokasi di desa Mananti, Kecamatan Huta Raja Tinggi Kabupaten Padang Lawas Sumatera Utara. Pelaksanaan penelitian dilakukan pada semester ganjil yaitu pada bulan desember 2019. Sampel penelitian adalah sebanyak 179 santri dan wawancara kepada pimpinan pesantren, kepala sekolah dan pembimbing ekstrakurikuler.

Pengumpulan data dilakukan bertujuan untuk memperoleh gambaran tentang evaluasi terhadap program ekstrakulikuler di pondok pesantren Alkhoir. [7] Teknik pengumpulan data yang digunakan berupa data penelitian kualitatif dan kuantitatif Adapun teknik pengambilan datanya adalah sebagai berikut:

Data penelitian kualitatif diperoleh dari observasi, wawancara. [8] Data penelitian kuantitatif diperoleh dari pengisian angket dari responden. Kuisioner disusun berdasarkan model evaluasi CIPP dengan menggunakan scala licert yaitu dengan lima alternative jawaban dengan tabel 2.

Tabel 2. Indikator variabel skala likert [9]

\begin{tabular}{|c|c|}
\hline Indikator Variabel & Skor \\
\hline Selalu & 5 \\
Sering & 4 \\
Kadang-kadang & 3 \\
Jarang & 2 \\
Tidak Pernah & 1 \\
\hline
\end{tabular}

Instrument disusun berdasarkan kajian teori, kemungkinan dikembangkan menjadi sub indikator. Untuk selengkapnya dapat dilihat ditabel 3.

Tabel 3.Kisi-kisi Isntrumen Penelitian

\begin{tabular}{|c|c|c|}
\hline No & Indikator & Butir Instrumen \\
\hline 1 & Context & $\begin{array}{l}\text { - Tujuan Program } \\
\text { - Kebutuhan Program } \\
\text { - Lingkungan Program }\end{array}$ \\
\hline 2 & Input & $\begin{array}{l}\text { - SDM } \\
\text { - Sarana dan Prasarana } \\
\text { - Aturan Pelaksanaan }\end{array}$ \\
\hline 3 & Process & $\begin{array}{l}\text { - Pelaksanaan Program } \\
\text { - Hambatan Program }\end{array}$ \\
\hline 4 & Product & - Hasil Pelaksanaan Program \\
\hline
\end{tabular}

Data kuantitatif akan diambil data penelitian dari santri yang mengikuti ekstrakurikuler, adapun jumlah populasinya adalah sebanyak 355 santri yaitu terbagi darikelas 1 hingga kelas 6 .

Tabel 4. Sumber Data

\begin{tabular}{|c|c|c|}
\hline No. & Kelas & Jumlah \\
\hline $\mathbf{1}$ & 1 & 80 \\
\hline $\mathbf{2}$ & 2 & 65 \\
\hline $\mathbf{3}$ & 3 & 60 \\
\hline $\mathbf{4}$ & 4 & 30 \\
\hline $\mathbf{5}$ & 5 & 60 \\
\hline $\mathbf{6}$ & 6 & 60 \\
\hline
\end{tabular}


Kemudian dihitung nilai akhir dengan menganalisis menggunakan rumus Slovin [10]

Keterangan:

$$
n=\frac{N}{1+N e^{2}}
$$

$$
\begin{aligned}
& n=\text { jumlah sampel } \\
& \mathrm{N}=\text { jumlah populasi } \\
& \mathrm{e}=\text { perkiraan tingkat kesalahan } \\
& 5 \%
\end{aligned}
$$

Berdasarkan nilai akhir yang diperoleh, kemudian dapat dikategorikan sesuai dengan tingkat ketercapaianya, seperti pada tabel 5 .

Tabel 5. Kategori Penguasaan[11]

\begin{tabular}{|c|c|l|}
\hline No & $\begin{array}{c}\text { Tingkat Pencapaian } \\
(\%)\end{array}$ & \multicolumn{1}{|c|}{ Kategori } \\
\hline 1 & $90-100$ & Sangat Baik \\
2 & $80-89$ & Baik \\
3 & $67-79$ & Cukup \\
4 & $55-64$ & Kurang \\
5 & $0-54$ & Kurang Sekali \\
\hline
\end{tabular}

\section{HASIL DAN PEMBAHASAN}

Hasil dan pembahasan ini berdasarkan hasil penelitian evaluasi program minat dan bakat yaitu dengan menggunakan model CIPP. Adapun hasil dari penelitian ini diperoleh dari angket dan data serta informasi yang didapatkan selama di

\begin{tabular}{|c|c|c|c|}
\hline No & Kegiatan & Waktu & Pembimbing \\
\hline 1 & Pramuka & $\begin{array}{c}\text { Kamis } \\
14.00-15.30\end{array}$ & $\begin{array}{c}\text { Desi } \\
\text { Purnama }\end{array}$ \\
\hline 2 & Muhadharah & $\begin{array}{c}\text { Senin } \\
20.00-21.30\end{array}$ & Guru Asram \\
\hline 3 & Computer & $\begin{array}{c}\text { Senis, rabu, kamis } \\
17.00-18.00\end{array}$ & $\begin{array}{c}\text { Desi } \\
\text { Purnama }\end{array}$ \\
\hline 4 & Study Club & $\begin{array}{l}\text { Senin, rabu } \\
17.00-18-00\end{array}$ & Maslijah \\
\hline 5 & Menjahit & $\begin{array}{l}\text { Setiap Hari } \\
17.00-18.00\end{array}$ & $\begin{array}{l}\text { Fathul } \\
\text { Jannah }\end{array}$ \\
\hline 6 & Tata Boga & $\begin{array}{l}\text { Minggu, senin, } \\
\text { selasa } \\
17.00-18.00\end{array}$ & $\begin{array}{c}\text { Nurhasanah } \\
\text { Harahap }\end{array}$ \\
\hline 7 & Pancak silat & $\begin{array}{l}\text { Selasa, rabu, } \\
17.00-18.00\end{array}$ & $\begin{array}{l}\text { Muhammad } \\
\text { Jutawan }\end{array}$ \\
\hline 8 & $\begin{array}{l}\text { Kitab } \\
\text { Kuning }\end{array}$ & $\begin{array}{c}\text { Kamis } \\
20.30-22.30\end{array}$ & $\begin{array}{c}\text { Habibul } \\
\text { Malik }\end{array}$ \\
\hline
\end{tabular}
lapangan. Adapun data pelaksanaan kegiatan ekstrakurikuler di pondok pesantren Al-khoir yaitu pada tabel 6:

Tabel 6. Kegiatan pelaksanaan Ekstrakurikuler
Berdasarkan tabel diatas dapat disimpulkan bahwa pelaksanaan program ekstrakurikuler diadakan pada sore hari, dan dilaksanakan setiap harinya sesuai dengan yang diikuti santri.

Komponen context terbagi atas tiga indikator yaitu tujuan program, kebutuhan program dan

\begin{tabular}{|c|c|c|c|c|c|c|c|c|}
\hline \multirow{3}{*}{$\begin{array}{l}\text { Indik } \\
\text { ator }\end{array}$} & \multicolumn{5}{|c|}{ Kriteria Pernyataan } & \multirow{3}{*}{$\begin{array}{l}\mathrm{Ra} \\
\mathrm{ta}^{2}\end{array}$} & \multirow{3}{*}{$\begin{array}{l}\mathrm{TC} \\
\mathrm{R}\end{array}$} & \multirow{3}{*}{$\begin{array}{l}\text { Kate } \\
\text { gori }\end{array}$} \\
\hline & $\begin{array}{l}\mathrm{S} \\
\mathrm{L}\end{array}$ & $\begin{array}{l}\mathrm{S} \\
\mathrm{R}\end{array}$ & $\begin{array}{l}\mathrm{K} \\
\mathrm{K}\end{array}$ & $\begin{array}{l}\mathrm{J} \\
\mathrm{R}\end{array}$ & $\begin{array}{l}\mathrm{T} \\
\mathrm{P}\end{array}$ & & & \\
\hline & $\%$ & $\%$ & $\%$ & $\%$ & $\%$ & & & \\
\hline Tujuan & 47 & 34 & 14 & 4 & 1 & 4 & 83 & Baik \\
\hline $\begin{array}{c}\text { Kebutu } \\
\text { han }\end{array}$ & 43 & 28 & 22 & 5 & 1 & 4 & 83 & Baik \\
\hline $\begin{array}{c}\text { Lingku } \\
\text { ngan }\end{array}$ & 31 & 43 & 23 & 3 & 0 & 4 & 81 & Baik \\
\hline \multicolumn{6}{|c|}{ Rata-Rata } & 4 & 82 & Baik \\
\hline
\end{tabular}
lingkungan program untuk penyajian secara kuantitatif ketiga indikator adalah sebagai berikut.

Tabel 7. Rekapitalisasi Tingkat Capaian Responden context.

Diperjelas dengan grafik komponen context pada gambar 2 sebagai berikut:

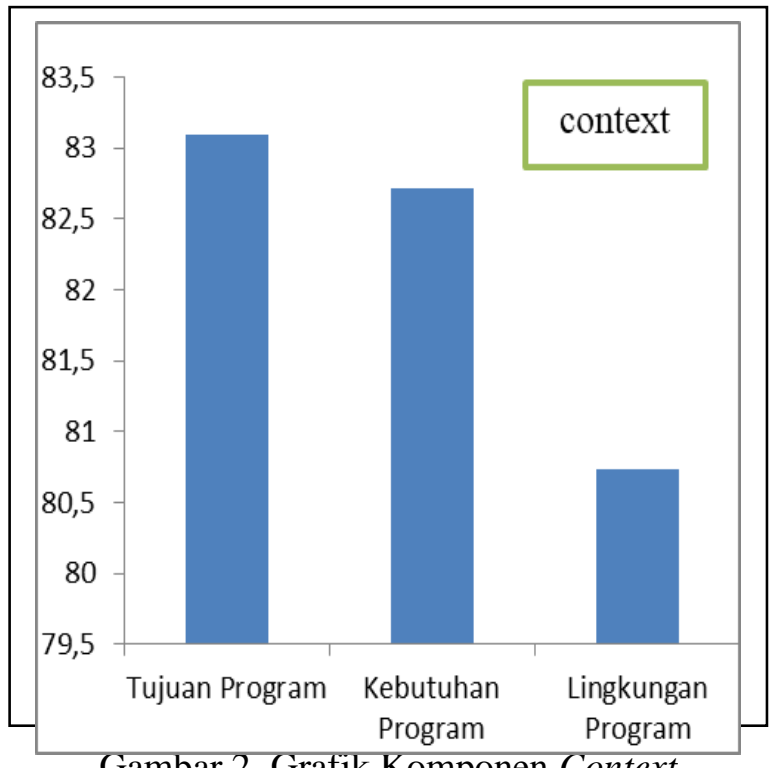

Gambar 2. Grafik Komponen Context

Berdasarkan tabel dan grafik komponen context diatas bahwa Indikator tujuan program ekstrakulikuler. Berdasarkan data hasil pengolahan kuisioner yang disebarkan kepada 179 santri pada program ekstrakurikuler memiliki persentase sebesar 46,68 \% mengatakan selalu, $34,14 \%$ mengatakan sering, 14,28\% mengatakan kadang-kadang, 3,85\% mengatakan jarang, dan 
$1,05 \%$ mengatakan tidak pernah. Indikator tujuan program ekstrakurikuler diperoleh skor rata-rata $4,14 \%$. Skor ideal maksimum adalah 5 dan tingkat capaian responden adalah $83,09 \%$ dengan kategori penilaian baik. Dengan demikian dapat diartikan bahwa tujuan dari program ekstrakurikuler sudah baik.

Indikator kebutuhan program ekstrakulikuler. Berdasarkan data hasil pengolahan kuisioner yang disebarkan kepada 179 santri pada program ekstrakurikuler memiliki persentase sebesar 43,39\% mengatakan selalu, 28,49\% mengatakan sering, 21,97\% mengatakan kadang-kadang, $4,85 \%$ mengatakan jarang, dan $1,30 \%$ mengatakan tidak pernah. Indikator kebutuhan program ekstrakurikuler diperoleh skor rata-rata $4,18 \%$. Skor ideal maksimum adalah 5 dan tingkat capaian responden adalah $82,72 \%$ dengan kategori penilaian baik. Dengan demikian dapat diartikan bahwa program ini di butuhkan dengan baik.

Indikator lingkungan program ekstrakulikuler. Berdasarkan data hasil pengolahan kuisioner yang disebarkan kepada 179 santri pada program ekstrakurikuler memiliki persentase sebesar $30,73 \%$ mengatakan selalu, $42,74 \%$ mengatakan sering, 23,18\% mengatakan kadang-kadang, $3,35 \%$ mengatakan jarang, dan $0,00 \%$ mengatakan tidak pernah. Indikator lingkungan program ekstrakurikuler diperoleh skor rata-rata $3,92 \%$. Skor ideal maksimum adalah 5 dan tingkat capaian responden adalah $80,73 \%$ dengan kategori penilaian baik. Dengan demikian dapat diartikan bahwa lingkungan program ekstrakurikuler sudah baik.

Berdasarkan nilai perolehan rata-rata dari indikator komponen product evaluasi program ekstrakurikuler dengan tingkat capaian responden (TCR) $82,18 \%$ yaitu dalam kategori baik. Dengan demikian ini perlu dipertahankan dan terus dikembangkan atau inovasi untuk mendapatkan hasil yang lebih baik.

Komponen input terbagi atas empat indikator yaitu sumber daya manusia, sarana dan prasarana, pendanaan atau biaya, aturan pelaksanaan program untuk penyajian secara kuantitatif empat indikator.

Berdasarkan tabel 8 dan grafik komponen input bahwa Sumber daya manusia program ekstrakulikuler. Berdasarkan data hasil pengolahan kuisioner yang disebarkan kepada 179 santri pada program ekstrakurikuler memiliki persentase sebesar $48,14 \%$ mengatakan selalu, $27,77 \%$ mengatakan sering, $15,81 \%$ mengatakan kadang-kadang, 5,25\% mengatakan jarang, dan $3,03 \%$ mengatakan tidak pernah. Indikator sumber daya manusia program ekstrakurikuler diperoleh skor rata-rata 4,29\%. Skor ideal maksimum adalah 5 dan tingkat capaian responden adalah $82,03 \%$ dengan kategori penilaian baik.

Tabel 8. Rekapitulasi Tingkat Capaian Responden input.

\begin{tabular}{|c|c|c|c|c|c|c|c|c|}
\hline \multirow[b]{2}{*}{ Indikator } & \multicolumn{5}{|c|}{ Kriteria Pernyataan } & \multirow[b]{2}{*}{$\begin{array}{l}\text { Rata } \\
2\end{array}$} & \multirow[b]{2}{*}{ TCR } & \multirow[b]{2}{*}{$\begin{array}{l}\text { Kateg } \\
\text { ori }\end{array}$} \\
\hline & $\begin{array}{l}\mathrm{S} \\
\mathrm{L}\end{array}$ & $\begin{array}{l}S \\
\mathrm{R}\end{array}$ & $\begin{array}{l}\mathrm{K} \\
\mathrm{K}\end{array}$ & JR & $\mathrm{TP}$ & & & \\
\hline & $\%$ & $\%$ & $\%$ & $\%$ & $\%$ & & & \\
\hline $\begin{array}{l}\text { Sumber } \\
\text { Daya } \\
\text { Manusia }\end{array}$ & 48 & 28 & 16 & 5 & 3 & 4 & 82 & Baik \\
\hline $\begin{array}{l}\text { Sarana } \\
\text { Dan } \\
\text { Prasarana }\end{array}$ & 52 & 17 & 13 & 8 & 11 & 5 & 77 & $\begin{array}{l}\text { Cuku } \\
\text { p }\end{array}$ \\
\hline $\begin{array}{l}\text { Biaya } \\
\text { Program }\end{array}$ & 60 & 13 & 11 & 9 & 2 & 4 & 77 & $\begin{array}{l}\text { Cuku } \\
\mathrm{p}\end{array}$ \\
\hline $\begin{array}{l}\text { Aturan } \\
\text { Pelaksana } \\
\text { an }\end{array}$ & 23 & 48 & 10 & 5 & 10 & 5 & 85 & Baik \\
\hline & & ta-R & & & & 4 & 80 & Baik \\
\hline
\end{tabular}

Diperjelas dengan grafik komponen input pada gambar 3

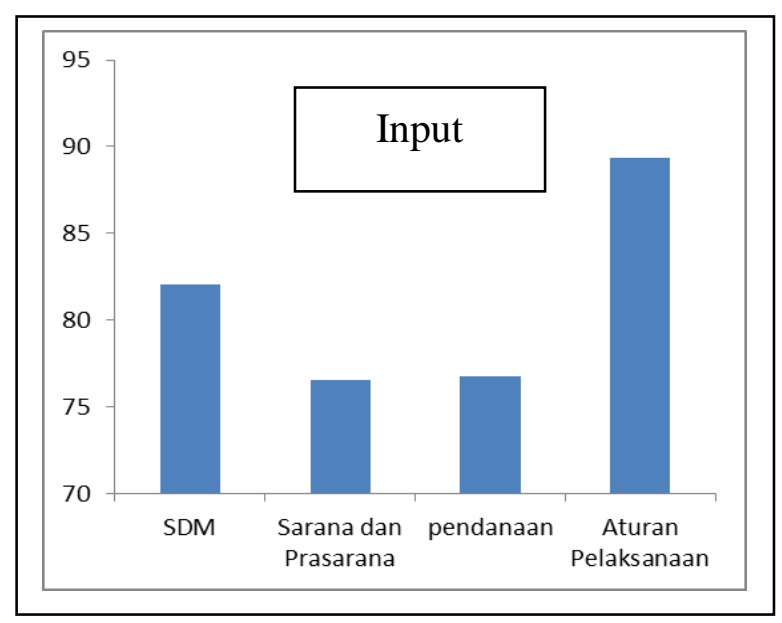

Gambar 3. Grafik Komponen Input. 
Dengan demikian dapat diartikan bahwa sumber daya manusia dari program ekstrakurikuler sudah baik. Sarana dan prasarana program ekstrakulikuler. Berdasarkan data hasil pengolahan kuisioner yang disebarkan kepada 179 santri pada program ekstrakurikuler memiliki persentase sebesar 51,58\% mengatakan selalu, 16,95\% mengatakan sering, $12,88 \%$ mengatakan kadang-kadang, $8,08 \%$ mengatakan jarang, dan $10,51 \%$ mengatakan tidak pernah. Indikator sarana dan prasarana program ekstrakurikuler diperoleh skor rata-rata 4,55\%. Skor ideal maksimum adalah 5 dan tingkat capaian responden adalah $76,55 \%$ dengan kategori penilaian cukup. Dengan demikian dapat diartikan bahwa sarana dan prasarana dari program ekstrakurikuler sudah masih cukup.

Pendanaan atau biaya program ekstrakulikuler. Berdasarkan data hasil pengolahan kuisioner yang disebarkan kepada 179 santri pada program ekstrakurikuler memiliki persentase sebesar $60,34 \%$ mengatakan selalu, $13,13 \%$ mengatakan sering, $10,50 \%$ mengatakan kadang-kadang, $8,52 \%$ mengatakan jarang, dan 1,99\% mengatakan tidak pernah. Indikator biaya/pendanaan program ekstrakurikuler diperoleh skor rata-rata 4,11\%. Skor ideal maksimum adalah 5 dan tingkat capaian responden adalah 76,67\% dengan kategori penilaian cukup. Dengan demikian dapat diartikan bahwa biaya/pendanaan dari program ekstrakurikuler masih cukup.

Aturan pelaksanaan program ekstrakulikuler. Berdasarkan data hasil pengolahan kuisioner yang disebarkan kepada 179 santri pada program ekstrakurikuler memiliki persentase sebesar 27,77\% mengatakan selalu, 48,14\% mengatakan sering, $10,25 \%$ mengatakan kadang-kadang, 5,25\% mengatakan jarang, dan 9,09\% mengatakan tidak pernah. Indikator aturan pelaksanaan program ekstrakurikuler diperoleh skor rata-rata 4,52\%. Skor ideal maksimum adalah 5 dan tingkat capaian responden adalah $85,39 \%$ dengan kategori penilaian baik. Dengan demikian dapat diartikan bahwa aturan pelaksanaan dari program ekstrakurikuler sudah baik.

Berdasarkan nilai perolehan rata-rata dari empat indikator komponen input evaluasi program ekstrakurikuler dengan tingkat capaian responden (TCR) 80,16\% yaitu dalam kategori baik. Dengan demikian ini perlu dipertahankan dan terus dikembangkan atau inovasi untuk mendapatkan hasil yang lebih baik.

Komponen process terbagi atas dua indikator yaitu pelaksanaan program dan hambatan program untuk penyajian secara kuantitatif kedua indikator.

Berdasarkan tabel 9 dan grafik komponen process gambar 4 bahwa Pelaksanaan program ekstrakulikuler Berdasarkan data hasil pengolahan kuisioner yang disebarkan kepada
179 santri pada program ekstrakurikuler memiliki persentase sebesar $51,55 \%$ mengatakan selalu, $28,77 \%$ mengatakan sering, 7,26\% mengatakan kadang-kadang, 1,30\% mengatakan jarang, dan $1,12 \%$ mengatakan tidak pernah. Indikator pelaksanaan program ekstrakurikuler diperoleh skor rata-rata $4,60 \%$. Skor ideal maksimum adalah 5 dan tingkat capaian responden adalah $78,08 \%$ dengan kategori penilaian cukup. Dengan demikian dapat diartikan pelaksanaan dari program ekstrakurikuler masih cukup.

Tabel 9. Rekapitulasi Tingkat Capaian Responden Process.

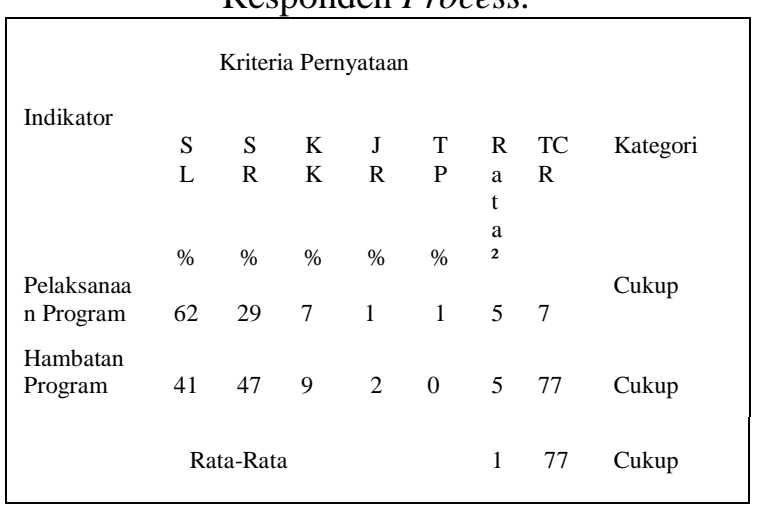

Diperjelas dengan grafik komponen process pada gambar 4.

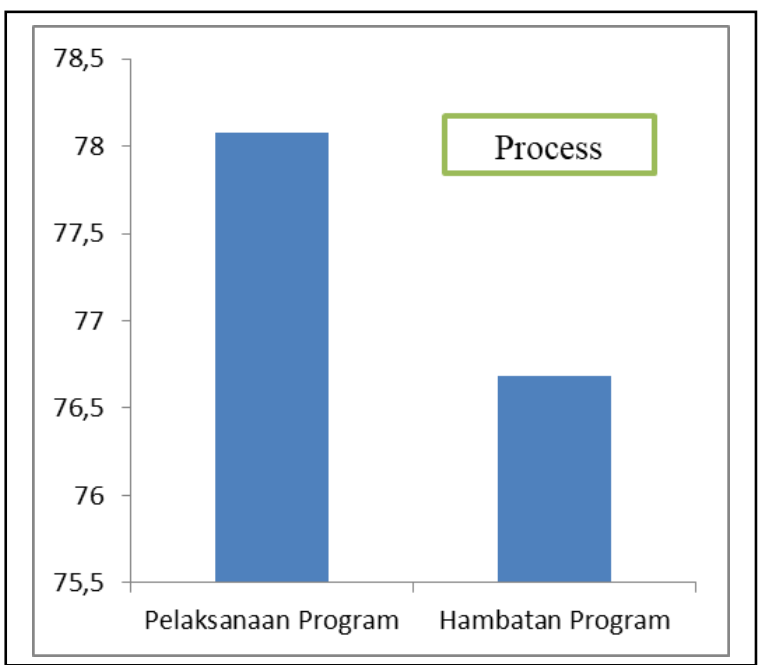

Gambar 4. Grafik Komponen process.

Hambatan program ekstrakulikuler. berdasarkan data hasil pengolahan kuisioner yang disebarkan kepada 179 santri pada program ekstrakurikuler memiliki persentase sebesar 41,27\% mengatakan selalu, 47,27\% mengatakan sering, 9,22\% mengatakan kadang-kadang, $1,96 \%$ mengatakan jarang, dan $0,28 \%$ mengatakan tidak pernah. Indikator hambatan 
program ekstrakurikuler diperoleh skor rata-rata 4,68\%. Skor ideal maksimum adalah 5 dan tingkat capaian responden adalah $76,68 \%$ dengan kategori penilaian cukup. Dengan demikian dapat diartikan bahwa pelaksanaan dari program ekstrakurikuler masih cukup.

Berdasarkan nilai perolehan rata-rata dari dua indikator komponen process evaluasi program ekstrakurikuler dengan tingkat capaian responden (TCR) $77,38 \%$ yaitu dalam kategori cukup. Dengan demikian ini mendapatkan perhatian untuk lebih lebih baiknya kedepan hingga menjadi ebih baik.

Komponen product terbagi atas satu indikator yaitu hasil pelaksanaan program untuk penyajian secara kuantitatif indikator.

Berdasarkan table 10 dan grafik komponen context gambar 5 bahwa Indikator hasil pelaksanaan program ekstrakurikuler diperoleh skor rata-rata $4,35 \%$. Skor ideal maksimum adalah 5 dan tingkat capaian responden adalah $81,73 \%$ dengan kategori penilaian baik. Dengan demikian dapat diartikan bahwa hasil pelaksanaan dari program ekstrakurikuler sudah baik.

Berdasarkan nilai perolehan rata-rata dari indikator komponen product evaluasi program ekstrakurikuler dengan tingkat capaian responden (TCR) $81,73 \%$ yaitu dalam kategori baik. Dengan demikian ini perlu dipertahankan dan terus dikembangkan atau inovasi untuk mendapatkan hasil yang lebih baik.

Komponen context juga memperoleh hasil atau dalam kategori baik. Oleh sebab itu maka penelitian ini tidak berbeda dengan penelitian yang telah dilakukan (Wajar). Akan tetapi, walaupun penelitian ini sudah dalam kategori baik akan tetapi harus tetap dioptimalkan untuk mendapatkan hasil yang lebih baik dan dapat dimanfaatkan oleh sekolah lain. Dalam evaluasi konteks perlu ditingkatkan lagi agar menghasil yang lebih berkualitas, setidaknya bisa mempertahankan kualitasnya sehingga selalu diterima pengguna. [12].

Komponen input termasuk dalam kategori baik. Akan tetapi, pada biaya atau pendanaan dan sarana dan prasarana berdasarkan masih dalam kategori cukup. Dengan demikian bahwa sarana dan prasarana yang tersedia belum mencukupi atau masih kuring. Pendanaan dalam program ini tidak seluruhnya dari pihak sekolah akan tetapi juga dibantu dari santri dengan sepengetahuan orang tua. Sarana dan Prasarana bahwa sarana dan prasarana pendidikan merupakan salah satu sumber daya yang penting dalam menunjang proses pembelajaran di sekolah. [13]

Tabel 10. Rekapitulasi Tingkat Capaian Responden input.

\begin{tabular}{|c|c|c|c|c|c|c|c|c|c|}
\hline \multirow{3}{*}{$\begin{array}{l}\mathrm{N} \\
\mathrm{o}\end{array}$} & \multirow{3}{*}{$\begin{array}{l}\text { Indikat } \\
\text { or }\end{array}$} & \multicolumn{5}{|c|}{ Kriteria Pernyataan } & \multirow{3}{*}{$\begin{array}{l}\text { Rat } \\
a^{2}\end{array}$} & \multirow{3}{*}{$\begin{array}{l}\mathrm{TC} \\
\mathrm{R}\end{array}$} & \multirow{3}{*}{$\begin{array}{l}\text { Kateg } \\
\text { ori }\end{array}$} \\
\hline & & $\begin{array}{l}\mathrm{S} \\
\mathrm{L}\end{array}$ & $\begin{array}{l}\mathrm{S} \\
\mathrm{R}\end{array}$ & $\begin{array}{l}\mathrm{K} \\
\mathrm{K}\end{array}$ & $\begin{array}{l}\mathrm{J} \\
\mathrm{R}\end{array}$ & $\begin{array}{l}\mathrm{T} \\
\mathrm{P}\end{array}$ & & & \\
\hline & & $\%$ & $\%$ & $\%$ & $\%$ & $\%$ & & & \\
\hline 1 & $\begin{array}{l}\text { Hasil } \\
\text { Pelaksa } \\
\text { naan } \\
\text { Progra } \\
\text { m } \\
\end{array}$ & 61 & 18 & 15 & 3 & 4 & 4 & 82 & Baik \\
\hline \multicolumn{7}{|c|}{ Rata-Rata } & 4 & 82 & Baik \\
\hline
\end{tabular}

Diperjelas dengan grafik komponen product pada gambar 5.

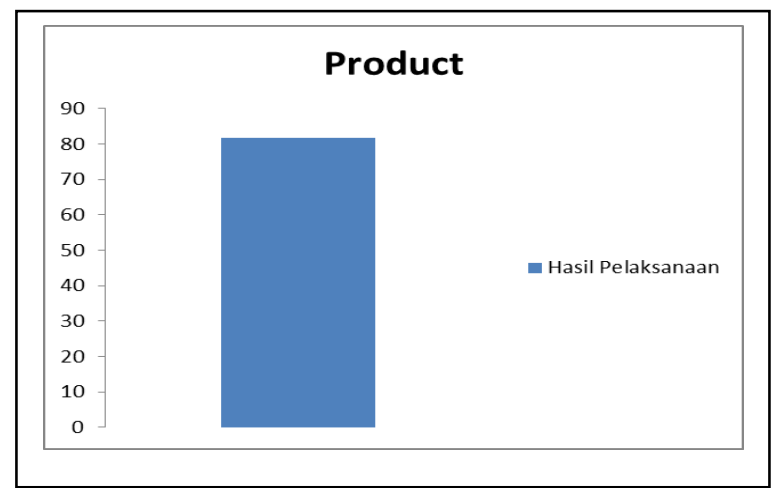

Gambar 5. Grafik Komponen product.

komponen proses termasuk dalam kategori cukup. Oleh sebab itu pelaksanaan dan hambatan program ekstrakurikuler perlu diperhatikan serta perlu ada perbaikn pada komponen ini demi kebaikan kedepannya program. [14]

Dalam komponen input perlu untuk selalu teliti dalam menentukan stategi guna menghasilkan langkah yang efektif. [15]

Evaluasi produk merupakan sebuah keputusan yang telah disusun ulang dengan menjawab sebuah pertanyaan, apakah tujuan sudah tercapai dengan hasil yang memuaskan. [16] 


\section{KESIMPULAN .}

Berdasarkan hasil penelitian Evaluasi Program ekstrakulikuler Pondok Pesantren Alkhoir Padang Lawas Sumatera Utara yang telah dilakukan. Context yang ada dalam program kegiatan ekstrakulikuler yang ditinjau dari tujuan Program, kebutuhan program, dan lingkungan program termasuk dalam kategori baik. Input yang dibutuhkan program kegiatan ekstrakulikuler Pondok Pesantren Al-khoir Padang Lawas Sumatera Utara ditinjau dari sumber daya manusia, sarana dan prasarana, biaya program ekstrakulikuler, dan aturan pelaksanaan termasuk dalam kategori baik. Process yang terdapat pada program kegiatan ekstrakulikuler Pondok Pesantren Al-khoir Padang Lawas Sumatera Utara ditinjau dari pelaksanaan program, hambatan program termasuk dalam kategori sangat baik. Product yang telah dicapai program kegiatan ekstrakulikuler Pondok Pesantren Al-khoir Padang Lawas Sumatera Utara ditinjau dari hasil pelaksanaan program termasuk dalam kategori baik.

\section{DAFTAR PUSTAKA}

[1] Permendikbud No. 62 Tahun 2014 tentang Kegiatan Ekstrakurikuler.

[2] Permendikbud No. 63 Tahun 2014 tentang Kegiatan Ekstrakurikuler.

[3] Nurhayati \& Anin. "Inovasi Kurikulum: Telaah terhadap Pengembangan Kurikulum Pesantren". Yogyakarta: Teras. 2010.

[4] Arikunto dan Jabar. "Evaluasi Program Pendidikan. Pedoman teoritis Praktis Bagi Mahasiswa dan Praktisi Pendidikan". Jakarta: Bumi Aksara, 2009.

[5] Farida Yusuf \& Tayibnafis, "Evaluasi Program dan Instrumen Evaluasi untuk Program Pendidikan dan penelitian" Jakarta: Rineka Cipta, 2008.

[6] Arikunto dan Jabar. "Evaluasi Program Pendidikan. Pedoman teoritis Praktis Bagi Mahasiswa dan Praktisi Pendidikan. Jakarta: Bumi Aksara, 2009.

[7] Arikunto. "Pedoman Teoritis Bagi Mahasiswa dan Praktisi Pendidikan". Jakarta: PT Bumi
Aksara.,2009.

[8] Arikunto, Suharsimi \& Abdul Jabar. "Evaluasi Program Pendidikan”. Jakarta: PT. Bumi Aksara, 2009.

[9] Miles, Matthew B, A. Michael Huberman dan Johnny Saldana. "Analisis Data Kualitatif". Jakarta: UI Press, 2014,

[10] Stufflebeam, Daniel. L \& Shinkfield, Anthony J. "Systematic evaluation: A Self-Instructional Guide to Theori and practice. San fransisco": jossey bass, 1988.

[11] Amirin, Tatang M. "Populasi dan sampel penelitian 4: Ukuran sampel rumus Slovin." 2011.

[12] Riduan. "Statistik". Bandung: Alfabeta, 2009.

[13] Tayibnapis \& Farida. "Evaluasi Program dan Instrumen Evaluasi untuk program pendidikan dan penelitian”. Jakarta: PT Rineka Cipta, 2008.

[14] Mulyatiningsih, Endang. "Metode Penelitian Terapan Bidang Pendidikan". Bandung: Alfabeta, 2011.

[15] Kelsey LD, Hearne CC. "Cooperative Extension Work”. Ithaca: Comstock Publishing Associates, 2005.

[16] Matin dan Nurhattati Fuad, "Manajemen Sarana dan Prasarana Pendidikan”. Jakarta: PT Raja Grafindo Persada, 2016.

\section{Biodata Penulis}

Nurhasanah Harahap, Lahir di panggulangan 12 september 1993. Memperoleh gelar Sarjana Pendidikan di Jurusan Pendidikan Kesejahteraan Keluarga Fakultas Pariwisata dan Perhotelan tahun 2017. Tahun 2018 menjalani jenjang S2 di jurusan Pendidikan Teknologi dan Kejuruan Fakultas Teknik Universitas Negeri Padangsekarang.

Fahmi Rizal, Lahir di Kamang Mudik tanggal 4 Desember 1959. Beliau lulus Sarjana (S1) pada tahun 1983 di Jurusan Teknik Bagunan IKIP Padang, Magister Pendidikan (S2) di IKIP Jakarta pada tahun 1992, Magister Teknik (S2) UGM Yogyakarta Pada Tahun 2000, dan Doktor (S3) dan Bidang Ilmu Pendidikan di Universitas Negeri Jakarta Pada Tahun 2007. 